\title{
Role of CT-PNS in non-neoplastic sino-nasal diseases: an observational study at tertiary care center in South Gujarat
}

\author{
Rahul B. Patel ${ }^{1}$, Nidhi R. Nair ${ }^{1 *}$, Jaymin A. Contractor ${ }^{1}$, \\ Jalpadevi A. Patel ${ }^{2}$, Ankita M. Vasani ${ }^{1}$
}

Department of ENT and Head \& Neck Surgery, ${ }^{1}$ Govt Medical College and New Civil Hospital, Surat, ${ }^{2}$ Community Health Center, Vyara, Surat, Gujarat, India

Received: 04 December 2018

Revised: 06 January 2019

Accepted: 07 January 2019

*Correspondence:

Dr. Nidhi R. Nair,

E-mail: chinz1106@gmail.com

Copyright: ( ) the author(s), publisher and licensee Medip Academy. This is an open-access article distributed under the terms of the Creative Commons Attribution Non-Commercial License, which permits unrestricted non-commercial use, distribution, and reproduction in any medium, provided the original work is properly cited.

\begin{abstract}
Background: Role of CT scan in sinonasal disease is proved by many published articles. Most of them are having small sample size, poorly defined protocol of CT reporting and does not mention the window width and window level of the software. We did this study to include these points and tried to have sample size of at least 200.

Methods: 231 patients included in the study. After clinical examination CT PNS was done. A strict protocol was maintained for the timing of CT, window settings (to get highest bony definition) and for the reporting of CT.

Results: Few common anatomical variations were agger nasi $(61.9 \%)$, DNS in $50.6 \%$; concha bullosa $(18.6 \%)$, paradoxical MT (20.3\%), Onodi Cells (21.6\%) and Haller cells (11.3\%). Most common subtypes amongst some anatomical variations include middle meatal drainage of frontal recess $(58.8 \%)$, type I frontal cell (7.1\%), type I ethmoid roof $(48.9 \%)$, type I attachment of UP (58.8\%) and sellar type of sphenoid pneumatization (68\%). CT has $100 \%$ sensitivity and specificity in detecting the diseased sinuses correctly. Except from $11.8 \%$ cases in which frontal recess drainage could not be assessed, all other anatomical variation were same intra-op as shown by CT. In fungal rhinosinusitis anatomical variations were difficult to detect by CT.

Conclusions: This study proves that CT-PNS gives us the detailed and near exact picture of the disease with its extent as well as of existing anatomical variations in non-neoplastic sino-nasal diseases except in FRS cases where in anatomical variations are difficult to analyze.
\end{abstract}

Keywords: CT PNS, Non-neoplastic sinonasal diseases

\section{INTRODUCTION}

The introduction of computed tomography (CT) in to medicine in the early 1970's ushered in a new era in the history of diagnostic imaging. ${ }^{1}$ Since 1979 , when the first head CT scanner was introduced by Godfrey Hounsfield, CT has matured greatly and gained technological sophistication. $^{2} \mathrm{CT}$ is in its fifth decade of clinical use and has proved invaluable as a diagnostic tool.
The nasal passage and paranasal sinuses plays host to a wide spectrum of diseases and conditions which can be collectively termed as Sino-nasal disease. The sino-nasal pathologies include broad spectrum of conditions ranging from inflammatory to neoplasms, both benign and malignant. The radiological evaluation of sino-nasal diseases is very essential as the clinical findings in these cases may be non-specific. ${ }^{3}$

CT is the imaging modality of choice since the advent of Functional endoscopic sinus surgery (FESS). CT plays an 
important role in the pre-operative evaluation of patients considered for FESS. It is noe mandatory to evaluate PNS before FESS, as it provides a "Road Map" to guide the otolaryngologist during surgery and serves to direct the surgical approach. ${ }^{4}$

Before embarking on any trans-nasal Endoscopic Sinus Surgery (ESS), it is very desirable for an ENT surgeon to be able to read the CT- PNS slice by slice on their own in regards to anatomical variation and pathology. A thorough knowledge of radio-anatomy of PNS obtained by good CT (good scanning protocol especially the optimal window width and level) is must now.

We reviewed the different literatures available on this subject. We found out that there are many articles on this topic, though most of them are having small sample size \&/or poorly defined protocol of CT reporting. Many of them had not mentioned predefined window width and window level settings of the software used while reporting the CT-PNS which is very important in reporting of anatomical variation in extensive disease. We planned this study including these data and to have sample size of at least 200.

\section{Aims and objectives}

- To study the normal anatomical variations in nose and paranasal sinuses (PNS) on CT scans.

- To correlate intra-operative findings with CT findings in operated cases.

\section{METHODS}

Study was approved from the Institutional Review Board for Human research of our institute. This observational study was performed from July 2008 to Sept 2018 in Department of ENT-Head \& Neck Surgery of New Civil Hospital, Surat.

\section{Inclusion criteria}

Inclusion criteria were all patients of non neoplastic sinonasal pathologies.

\section{Exclusion criteria}

Exclusion criteria were all patients of neoplastic sinonasal pathologies detected at any stage; patients with past history of any nasal surgery

All patients satisfying inclusion criteria were included in the study. After detailed clinical examination of ENT, all underwent diagnostic nasal endoscopy (DNE) by Hopkins 0 degree Storz or Wolf telescopes under surface anesthesia.

We have maintained a strict protocol regarding timing of the CT in all patients. Before taking the date for CT, patients were given proper medical treatment if indicated.
For example, if patient had superadded viral/bacterial rhinosinusitis over and above primary sino-nasal pathology then CT was done only after extra symptoms of rhino-sinusitis resolved completely. Also in cases of bilateral ethmoidal polyposis, all were given appropriate medical treatment (oral and nasal steroid, anti-histaminic etc.) till at least 3 weeks before taking date for CT. At times, medical treatment was continued till 4 -6 weeks due to various factors like date for CT/surgery was not available at 3 weeks. Not surprisingly, it was found that all patients had 70 to $100 \%$ improvement in all or some nasal symptoms. Before the date of CT all were called for DNE with suction cleaning of nose, meati and nasopharynx to minimize the haziness of mucus on CT so that near exact reporting can be possible in regards to normal anatomical variations.

\section{CT Scans were done at following CT scan centers:}

Majority were done at Dept. of Radiodiagnosis \& Imaging, New Civil Hospital, Surat having Siemens Spiral Scanner- 6/16 slice (Forchheim, Germany).

Occasionally CT scans were done at three other private CT scan centers according to patient's choice as follows: 'Superscan' \& 'Concept Imaging' ( both having Toshiba Activion 16-Toshiba Medical Corporation, Japan), Radiology dept, BAPS Hospital (Somatom Duo Slice), 'Speedscan' (Siemens Sensation Cardiac, Germany).

When patients came with CT scan already done more than one month before presenting to us, without appropriate medical management (when indicated) \&/or without DNE, we obtained repeat CT scans after proper preparation as per our protocol. All patients who refused CT scan were excluded.

\section{Scanning protocol}

For axial sections scanning was done from roof of frontal sinus up to the hard palate with the patient in supine position with all sections parallel to hard palate. The sections were taken with slice thickness of $3 \mathrm{~mm}$. Scanning parameters included $70 \mathrm{~mA}, 130 \mathrm{kV}$ and tube rotation time of 1.0 seconds. When required, extended cephalic or caudal sections were also taken to see extension of the disease process.

Coronal sections were performed with the patients in prone position with extended neck and the plane of sections perpendicular to axial plane. The scan parameters were same as in axial plane.

Images were reconstructed at $1 \mathrm{~mm}$ intervals in coronal, axial and parasaggital.

The images thus generated were photographed at window width of $+1500-+2000$ and window level of $+100-+300$ for highest bony definition. ${ }^{5}$ On suspecting fungal 
disease, window setting was changed to soft tissue settings.

To maintain the uniformity in the reporting of the CT, it was done in pre-defined pre-tested reporting pro forma prepared with the help of radiologists. All reports and plates were re-evaluated by an ENT surgeon also and if any disparity in reporting occurs than conclusion was made by personal meeting with radiologist. Those cases that underwent surgery intra-op findings were recorded also according to the same pretested protocol to make it possible for comparison with CT findings. Data entry and analysis was done in MS-Excel.

Total 231 patients (462 sides) were available for analysis in our study. Out of 462 sides, 13 sides of fungal rhinosinusitis (FRS) patients were excluded to calculate prevalence of some anatomical variation, as they all had extensive fungal disease with bony erosions. So 449 has been considered as denominator for the same. For comparison between CT and Intr-op findings, 108 patients of ethmoidal polyposis (206 sides) and 9 patients of FRS ( 9 sides) in which b/l or $\mathrm{u} / \mathrm{l}$ complete FESS done ( $n=215$ sides), in regards to sinus involvement. For comparison of anatomical variation 108 cases of ethmoidal polyposis ( $n=206$ sides) were considered only.

\section{RESULTS}

We found that almost $60 \%$ of the patients belong to $11-30$ yrs of age group. Mean age was 28.2 years. Out of total patients, $58.49 \%$ patients were males while $41.51 \%$ were females. It shows male predominance by $3: 2$ (Table 1).

Table 1: Age wise distribution $(\mathrm{n}=231)$.

\begin{tabular}{|llll|}
$\begin{array}{l}\text { Sr. } \\
\text { No }\end{array}$ & $\begin{array}{l}\text { Age groups in } \\
\text { years }\end{array}$ & $\begin{array}{l}\text { No of } \\
\text { Patients }\end{array}$ & $\begin{array}{l}\text { Percentage } \\
(\%)\end{array}$ \\
\hline $\mathbf{1}$ & $\leq 10$ & 17 & 7.4 \\
\hline $\mathbf{2}$ & $11-20$ & 79 & 34.2 \\
\hline $\mathbf{3}$ & $21-30$ & 58 & 25.1 \\
\hline $\mathbf{4}$ & $31-40$ & 26 & 11.3 \\
\hline $\mathbf{5}$ & $41-50$ & 17 & 7.4 \\
\hline $\mathbf{6}$ & $51-60$ & 17 & 7.4 \\
\hline $\mathbf{7}$ & $\geq 60$ & 17 & 7.4 \\
\hline
\end{tabular}

\section{Common anatomical variations on CT Scans $(n=231)$}

Common anatomical variations in this study includes, agger nasi $61.9 \%$ (143), DNS in $50.6 \%$ (117), concha bullosa in $18.6 \%$ (43), paradoxical MT in $20.3 \%$ (47), onodi cells in $21.6 \%(50)$ and haller cells in $11.3 \%$ (26) cases. Amongst onodi cells, $13.8 \%$ were indirect type of Onodi cells while $\mathbf{7 . 7 \%}$ were direct +ve type. None of the case found to have direct -ve type.

In our study we found that middle meatus type of frontal sinus drainage pathway was most common found in $58.8 \%$ sides. Type I frontal cell was the most common found in $7.1 \%$ sides. Type I ethmoid roof was the most common found in $48.9 \%$ sides (Table 2 ).

Table 2: Prevalence of anatomical variations in frontal sinus drainage pathway and ethmoidal roof $(n=449)$.

\begin{tabular}{|c|c|c|c|}
\hline $\mathrm{Sr}$ & $\begin{array}{l}\text { Anatomical } \\
\text { variations }\end{array}$ & Sub types & $\begin{array}{l}\text { Prevalence } \\
(\%)\end{array}$ \\
\hline \multirow{3}{*}{1.} & \multirow{3}{*}{$\begin{array}{l}\text { Frontal recess } \\
\text { Drainage }\end{array}$} & $\begin{array}{l}\text { Infundibular } \\
\text { (open in } \\
\text { infundibulum) }\end{array}$ & $132(29.4)$ \\
\hline & & $\begin{array}{l}\text { Middle meatus } \\
\text { (open in } \\
\text { middle } \\
\text { meatus) }\end{array}$ & $264(58.8)$ \\
\hline & & $\begin{array}{l}\text { Could not be } \\
\text { assessed }\end{array}$ & 53 (11.8) \\
\hline \multirow{4}{*}{2.} & \multirow{4}{*}{$\begin{array}{l}\text { Frontal cells- } \\
\text { according Wormald } \\
\text { Modification }^{5}\end{array}$} & Type I & $32(7.1)$ \\
\hline & & Type II & $5(1.1)$ \\
\hline & & Type III & $3(0.7)$ \\
\hline & & Type IV & $2(0.4)$ \\
\hline \multirow{3}{*}{3.} & \multirow{3}{*}{$\begin{array}{l}\text { Ethmoid roof (Acc. to } \\
\text { Kero's classification) }\end{array}$} & Type I & $220(48.9)$ \\
\hline & & Type II & $179(39.8)$ \\
\hline & & Type III & $50(11.1)$ \\
\hline
\end{tabular}

Table 3: Prevalence of anatomical variations of uncinate process $(n=449)$.

\begin{tabular}{|c|c|c|c|}
\hline & Variation & Sub types & $\begin{array}{l}\text { Prevalence } \\
(\%)\end{array}$ \\
\hline \multirow{5}{*}{1.} & \multirow{5}{*}{$\begin{array}{l}\text { Uncinate } \\
\text { process }\end{array}$} & $\begin{array}{l}\text { Laterally bent } \\
\text { (atelectatic) }\end{array}$ & $27(6)$ \\
\hline & & Medially bent & $175(39)$ \\
\hline & & Pneumatized & $18(4)$ \\
\hline & & Horizontal & 0 \\
\hline & & $\begin{array}{l}\text { Normal (saggital } \\
\text { orientation) }\end{array}$ & $229(51)$ \\
\hline \multirow{4}{*}{2} & \multirow{4}{*}{$\begin{array}{l}\text { Uncinate } \\
\text { process } \\
\text { superior } \\
\text { attachment }\end{array}$} & $\begin{array}{l}\text { Type I (inserted to } \\
\text { lamina papyracea/AN) }\end{array}$ & $264(58.8)$ \\
\hline & & $\begin{array}{l}\text { Type II (inserted to } \\
\text { skull base) }\end{array}$ & $47(10.5)$ \\
\hline & & $\begin{array}{l}\text { TypeIII (inserted to } \\
\text { middle turbinate) }\end{array}$ & 85 (18.9) \\
\hline & & $\begin{array}{l}\text { Type IV (combination } \\
\text { of above) }\end{array}$ & $53(11.8)$ \\
\hline
\end{tabular}

We found that in $39 \%$ sides uncinate process was medially bent. Superior attachment of uncinate process was most commonly found to be inserted to lamina papyracea (58.8\% sides) (Table 3$)$.

Hypoplastic maxillary sinus was found in $5 \%$ cases. In sphenoid sinus most commonly single inter-sinus septum was most common found in $69 \%$ cases. Regarding sphenoid sinus pneumatization we observed that Sellar type was most common found in $68 \%$ cases (Table 4 ). 
Table 4: Prevalence of anatomical variations in maxillary and sphenoid sinus $(\mathrm{n}=\mathbf{2 3 1})$.

\begin{tabular}{|c|c|c|c|}
\hline $\begin{array}{l}\text { Sr. } \\
\text { No }\end{array}$ & Variations & Sub types & $\begin{array}{l}\text { Prevalence } \\
(\%)\end{array}$ \\
\hline 1. & Maxillary sinus & Hypoplastic & $21(5)$ \\
\hline \multirow[b]{2}{*}{2.} & \multirow[b]{2}{*}{ Sphenoid sinus } & $\begin{array}{l}\text { No of } \\
\text { chambers }\end{array}$ & $\begin{array}{l}1: 4 \% ; 2: 69 \% \\
3: 19 \% ; 4: 8 \%\end{array}$ \\
\hline & & $\begin{array}{l}\text { Inter sinus } \\
\text { septum } \\
\text { (SIS) ending } \\
\text { on }\end{array}$ & $\begin{array}{l}\text { ON:4 (1) } \\
\text { ICA:31 (6.9) }\end{array}$ \\
\hline \multirow{4}{*}{3.} & \multirow{4}{*}{$\begin{array}{l}\text { Sphenoid sinus } \\
\text { pneumatization }\end{array}$} & Conchal & $7(3)$ \\
\hline & & Pre sellar & $30(13)$ \\
\hline & & Sellar & 157 (68) \\
\hline & & Mixed & $37(16)$ \\
\hline
\end{tabular}

*ON- optic nerve, ICA - internal carotid artery.

\section{Sinus involvement $(n=462)$}

We found that ethmoid and maxillary sinuses were involved in $66.3 \%$ (309) sides each. This was followed by Frontal sinus and sphenoid sinus in $50.8 \%$ (237) and $39.9 \%$ (186) sides respectively.

\section{Comparison between CT findings and intra-op findings $(n=215)$}

This chart (Figure 1) shows that CT is 100 sensitive and specific in detecting the diseased sinuses.

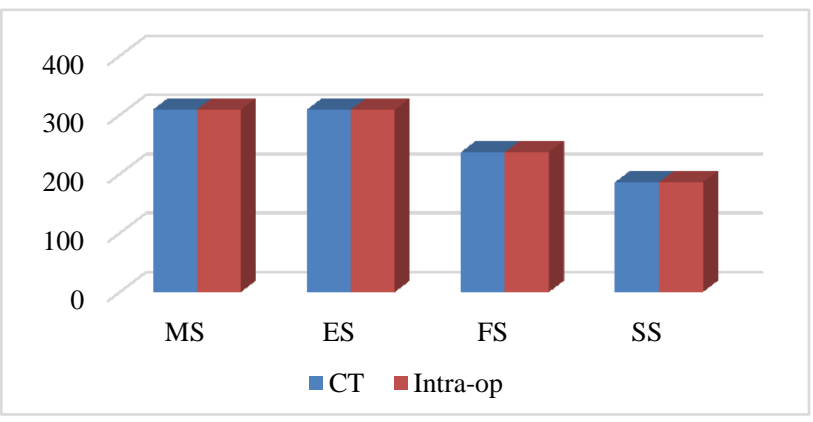

Figure 1: Prevalence of sinus involvement seen on CT and intra-op.

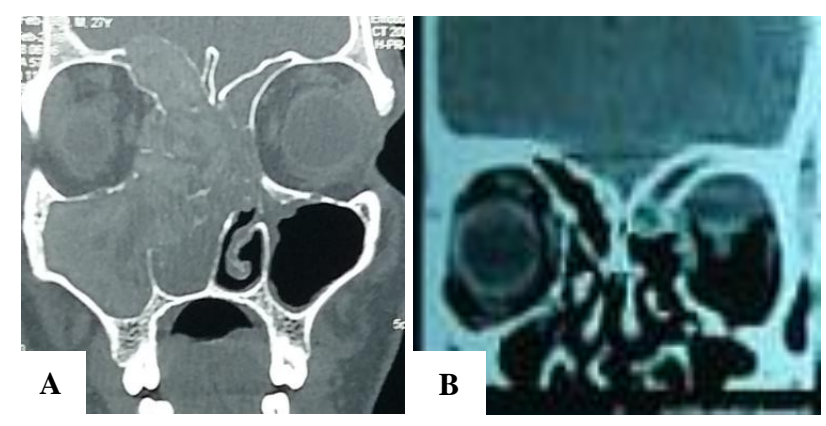

Figure 2: Coronal images of CT showing: (A) Rt fungal rhinosinusitis and (B) Lt frontal mucocele.
We also detected that except for one case of rhinolith which was not correctly diagnosed by CT, in all other cases (230 i.e. $99.6 \%$ cases), final diagnosis was matching the diagnosis/one of the differential diagnosis predicted by CT. Except for $11.8 \%$ cases (Table 2 ) in which type of frontal recess could not be assessed by $\mathrm{CT}$ and ethmoidal roof which could not be assessed intra-op according to Kero's classification, all other anatomical variation were same intra-op as shown by CT.

\section{Types of nonn eoplastic sinonasal diseases $(n=231)$}

Bilateral ethmoidal polyposis was the most common disease found in $48.4 \%$ (112) cases. This is followed in order by AC polyp-34.6\% (80), rhinosporidiosis$8.6 \%$ (20), fungal rhinosinusitis (FRS-Figure 2a)-5.1\% (12), Acute pansinusitis-1.7\% (4), frontal mucocele (Figure 2B)- $0.8 \%$ (2) and one case of rhinolith (0.4\%).

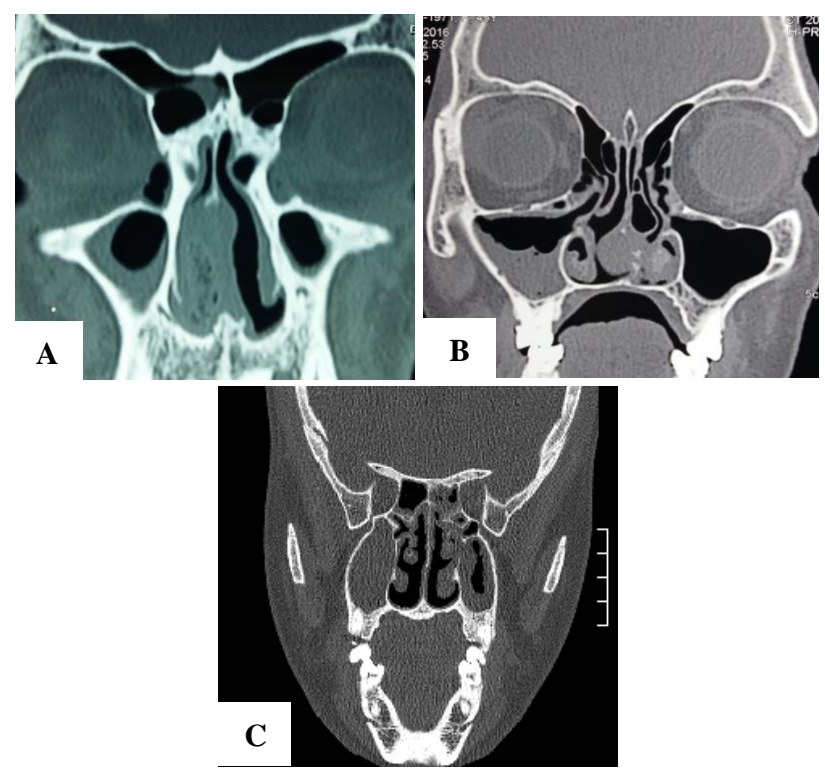

Figure 3: Coronal images of CT showing: (A) right type IV frontal cell \& Lt AN, (B) left concha bullosa and $(C)$ Rt paradoxical MT.

\section{Complications}

In the 217 cases which were operated, the complication rate was $1.8 \%$ (4 cases). This includes one case of FRS having intraop CSF leak which was repaired successfully in the same sitting. Two cases had intra-op orbital fat prolapse with post-op orbital swelling (? hematoma) all of them improved completely in 1 week. One case of FRS had temporary dimness of vision, which improved completely after 3 weeks of conservative treatment. 4 cases $(1.8 \%)$ had recurrence.

\section{DISCUSSION}

In this study patients having non neoplastic sino-nasal disease comprised patients of all age groups with 
maximum no of patients found in 11-30 yrs age group. (58.5\% of patients). Mean age of patient was 28 yrs.

The incidence of non-neoplastic sino-nasal disease was more in male $(58.5 \%)$ as compared to female $(33.3 \%)$ in our study. The higher incidence in male may be attributed to more exposure to external environment beside home, while females undertaken in the study were mostly housewives confined to houses which lessen the no and variety of pollutants.

Deviated nasal septum (DNS) was found in 50.6\% sides in this study, which is almost similar to that observed by Dua (44\%) and Maru (55.7\%) but more than Asruddin $(38 \%){ }^{6-8}$ DNS causes a decrease in the critical area of the osteomeatal unit predisposing to obstruction and related complication.
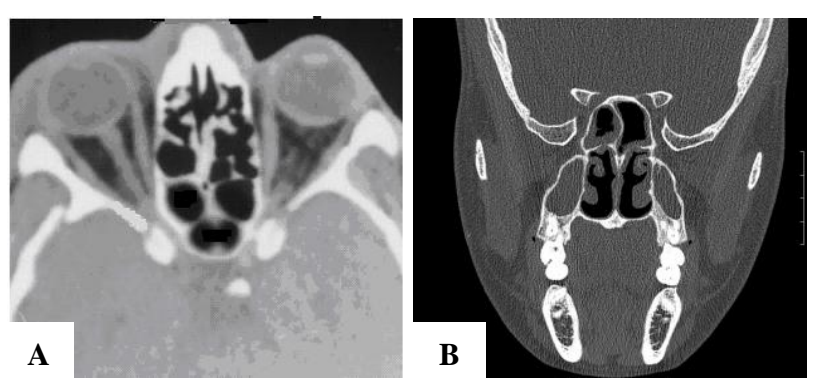

Figure 4: Coronal CT showing: (A) Onodi cells and (B) SIS ending on ICA.

Agger nasi cells (Figure 3a) were present in $61.9 \%$ sides in this study. Maru (88.5\%) Wormald (93\%) reported higher incidence than us while Stammberger (15\%) reported much lower incidence. ${ }^{7,9,10}$ Gupta $(68.8 \%)$ reported almost similar incidence to us. ${ }^{11}$ This wide variation in the proportions of agger nasi cells in different study populations make preoperative CT mandatory for their detection. Failure to detect and address them during surgery leads to inadequate removal of disease especially from frontal sinus and (or) recess.

Concha bullosa (Figure 3b) has been implicated as a possible etiological factor in the causation of recurrent chronic sinusitis. The incidence of concha bullosa was $18.3 \%$ in present study. It is less as compared to that reported by Maru (42.6\%), Asruddin (28\%) and Stammberger $(24 \%) .^{7,8,10}$ Dua $(16 \%)$ and Gupta $(11.5 \%)$ reported almost similar incidence. ${ }^{6,11}$

The middle turbinate may be paradoxically curved (Figure 3C) i.e. bent in the reverse direction. This may lead to impingement of middle meatus and thus to sinusitis. It is found in $20.3 \%$ sides in our study. It is almost similar to Stammberger $(15 \%) .{ }^{10}$ Dua (10\%), Maru (11.5\%), Asruddin (12\%) and Gupta (13\%) reported lower incidence. ${ }^{7,8,11}$

In our study, $21.6 \%$ sides had onodi cells (Figure 4A). Dua (6\%) Maru (9.8\%) and Asruddin (12\%), reported lower incidence..$^{6-8}$ Gupta $(47.8 \%)$ reported much higher incidence. ${ }^{11}$ On assessing the relation of optic nerve with Onodi cells we found that $13.8 \%$ were indirect type of Onodi cells while $7.7 \%$ were direct +ve type. None of the case found to have direct -ve type. The chances of injury to the optic nerve are increased when the bony canal of the nerve is lying dehiscent. Again pre op CT is the only measure to detect their presence and to avoid serious complication in this area like Optic nerve damage.

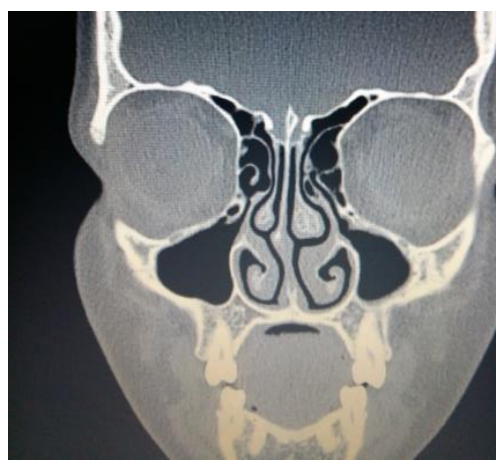

Figure 5: Coronal CT showing superior attachment of UP to lamina payracea (type I), Middle Meatus drainage of frontal recessand Kero's type I ethmoid roof on both sides.

The incidence of Haller's cells in our study is $6.6 \%$. Gupta $(3.62 \%)$ reported lower incidence. ${ }^{11}$ Dua $(16 \%)$, Maru (36.1\%), Asruddin (28\%), and Stammberger (13\%) reported higher incidence. ${ }^{6-8,11}$ Presence of Haller's cells may narrow the adjacent ostium of the maxillary sinus especially if they become infected. They also make the infundibulum narrow and deep making it further prone to blockage.

Frontal recess drainage in the middle meatus (Figure 5) was the most common (58.8\%). In $30.1 \%$ sides it opens in infundibulum. In $11.8 \%$ sides it could not be assessed by CT.

Frontal ethmoidal cells in this study were evaluated according to classification of Frontal sinus cells proposed by Wormald. ${ }^{9}$ We found prevalence of type I, type II, type III and type IV (Figure 3A) in $7.1 \%, 1.1 \%, 0.7 \%$ \& $0.4 \%$ respectively. Dhingra reported the incidence of these cells as $10 \%, 0 \%, 3.3 \%$ and $3.3 \%$ respectively. ${ }^{12}$ Gupta reported the incidence of these cells as $18.1 \%$, $2.2 \%, 4.3 \%$ and $4.3 \%$ respectively. $^{11}$

According to Kero's classification in this study, we found that type I (Figure 5) is the most common type (47\%) followed in order by type II (37.9\%) and type III $(11.6 \%)$. Gupta reported the incidence as $50 \%, 47.1 \%$ and $2.9 \%$ respectively. ${ }^{11}$ In our study, one of the patients of FRS with type III ethmoid roof had intra op CSF leak which could be successfully repaired in the same sitting. CT is the only way to detect the type of ethmoid roof and thus can prevent one of the serious complications of ESS viz. CSF leak. 
Zinreich first observed that the uncinate process (UP) may be curved or bent. The uncinate process was found in normal saggital orientation in $51 \%$ sides, medially bent in 39\%, laterally bent (atelectatic) in 6\% sides and pneumatized uncinate in $4 \%$ sides. Study done by Tulli found the same variations in $70 \%, 24 \%, 2 \%$ and $4 \%$ respectively. ${ }^{13}$ Laterally bent uncinate is most dangerous as chances of entering in the orbit is high. Same thing happened in our study in 2 cases intra-op having laterally bent uncinate.

Superior attachment of UP was assessed in four different types as shown in Table 3. In our study we found that type I attachment (attachment to lamina papyracea-Figure 5) was the most common $(58.8 \%)$. This is followed by type III $(18.9 \%)$ \& type II $(10.5 \%)$ sides. Wormald is of the same opinion that type I is the commonest and type II is the least common. ${ }^{9}$ Tulli reported that type I $(79.8 \%)$ and type II $(16.6 \%)$ is more common than type III $(3.5 \%) .{ }^{13}$ Though Hasan reported type III being the most common $(36.4 \%)$ followed by type I $(29.5 \%)$ and type II $(13.6 \%) .{ }^{14}$

In our study, single sphenoid intra-sinus septum (SIS) with two chambers was the most common entity which was observed in $69 \%$ sides or in $69 \%$ of sphenoid sinuses.

In $6.9 \%$ sides one of the SIS was ending on ICA (Figure 4b) while in $1 \%$ sides SIS was inserted on optic nerve. Gupta reported these percentages as $24.6 \%, 2 \%$ and $1 \%$ respectively. $^{8}$

Regarding sphenoid sinus pneumatization we detected that sellar is the most common type (68\%), followed in order by mixed (16\%), presellar $(13 \%)$ and conchal $(3 \%)$. Stammberger reported the same order of frequency with incidence being $59 \%, 27 \%, 11 \%$ and $3 \%$ respectively. ${ }^{10}$

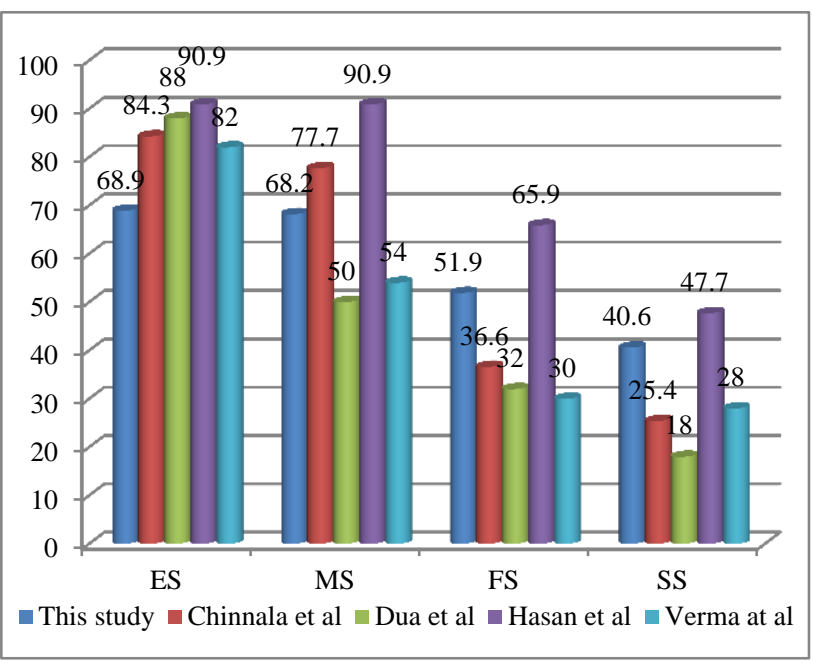

Figure 6: Prevalence of paranasal sinus involvement amongst different studies as compared to our study.
This chart (Figure 6) shows that in non-neoplastic sinonasal disease ethmoid and maxillary were the two most common sinuses to get involved and Sphenoid sinus was the least commonly involved one reported by our study and by different studies.

Except for the detection of frontal drainage pathway in $11.8 \%$ sides and detection of anatomical variations in cases of FRS, CT scan is almost $100 \%$ accurate in detection of the anatomical variations, sinus involvement and in predicting the diagnosis. In cases of FRS, having bone erosion we have observed that in some cases even with the best possible window width and level, it was very difficult to detect or analyze the anatomical variations in CT. However it was possible to identify such variations intra-op. Though to arrive at such a conclusion in this regards, a larger series of only FRS cases is required.

CT has helped us to keep the complication and recurrence rate down to $3 \%$ and $1.8 \%$ respectively, with none of them had a permanent damage.

\section{CONCLUSION}

This study proves that CT-PNS gives us the detailed accurate picture of the disease with its extent as well as of existing anatomical variations in non-neoplastic sinonasal diseases except in FRS cases where in anatomical variations are difficult to see

Comparison of intra-op findings with $\mathrm{CT}$ findings suggest that it is almost $100 \%$ accurate baring few exceptions. CT gives almost a virtual picture to the endonasal surgeon about what he/she will encounter intraoperatively while doing the actual surgery. This helps in making the surgery more meticulous and chances of complications and residual diseases are minimal. Thus, CT-PNS in almost like a Virtual tour of nasal passages and PNS before doing the actual ESS.

\section{ACKNOWLEDGEMENTS}

Besides the faculties and residents of Department of Radiodiagnosis and Imaging, New Civil Hospital, Surat who helped by reporting of the CT as needed for our study, the two radiologists Dr. G. Ardesana and Dr. N. Jindal need special mention for their role in helping us to develop reporting protocol of CT PNS.

Funding: No funding sources

Conflict of interest: None declared

Ethical approval: The study was approved by the Human Research Ethical Committee (HREC)

\section{REFERENCES}

1. Norbrt JP. Recent and future directions in CT imaging. Ann Biomed Eng. 2014;42(2):260-8. 
2. Kandukuri R, Phatak S. Evaluation of Sinonasal Diseases by Computed Tomography. J Clin Diagn Res. 2016;10(11):9-12.

3. Gonje NP. Computed Tomography in 2st Century: Current status \& future prospects. JIMSA. 2013;26(1):35-42.

4. Kushwah APS, Bhalse R, Pande S. CT evaluation of diseases of Paranasal sinuses \& histopathological studies. Int J Med Res Rev. 2015;3(11):1306-10.

5. Peter-John Wormald, Endoscopic Sinus SurgeryAnatomy, Three-Dimensional Reconstruction and Surgical Technique. 2nd ed. New York: Thieme; 2008:13.

6. Dua K, Chopra H, Khurana A, Munjal M. CT Scan variations in chronic sinusitis. Int J Otorhinolaryngol Head Neck Surg. 2005;15(3):31520.

7. Maru Y, Gupta V. Anatomic Variations of the Bone in sinonasal CT. Int J Otorhinolaryngol Head Neck Surg. 2001;53:123-8.

8. Asruddin, Yadav S, Yadav R, Singh J. Low dose CT in chronic sinusitis. Int $\mathrm{J}$ Otorhinolaryngol Head Neck Surg. 2000;52:17-22.

9. Peter-John Wormold, Endoscopic Sinus SurgeryAnatomy, Three-Dimensional Reconstruction and Surgical Technique. 2nd ed. New York: Thieme; 2008: 45-53.

10. Stammberger H, Lund VJ. Anatomy of nose and paranasal sinuses. In:Gleeson $\mathrm{M}$ et al, editors. ScottBrown's Otolaryngology, Head \& Neck Surgery
Vol-2. 7th ed. Great Britain: Hodder Arnold; 2008: 1335-1339.

11. Gupta A, Gupta B, Gupta N, Tripathi N. Computerized tomography:A roadmap to endoscopic sinus surgery. Clin Rhinol Int J. 2012;5(1):1-10.

12. Dhingra S, Agarwal AK, Passey J, Kaul J. Anatomical analysis of the frontal recess cells in Endoscopic Sinus Surgery-An Indian perspective. Clin Rhinol Int J. 2009;2(3):15-9.

13. Tuli I, Sengupta S, Munjal S, Kesari S, Chakraborty. Anatomical variations of Uncinate process observed in chronic sinusitis. Ind $\mathrm{J}$ OtoHNS. 2013;65(2):157-61.

14. Hassan O, Hassan M, Fawzy E, Maarouf A. Anatomical Variations of nasal structures in Chronic rhinosinusitis as detected by CT scan. EJHM, 2017;68(37):1390-4.

15. Chinnala S, Atkari R. CT Evalution of diseases of Paranasal sinuses. IJRSR. 2015;6(7):5081-5.

16. Verma J, Rathaur S, Mishra S, Mishra A. The Role of diagnostic imaging in evaluation of nasal and paranasal sinus pathology. Int J Otorhinolaryngol Head Neck Surg. 2016;2(3):140-6.

Cite this article as: Patel RB, Nair NR, Contractor JA, Patel JA, Vasani AM. Role of CT-PNS in non-neoplastic sino-nasal diseases: an observational study at tertiary care center in South Gujarat. Int J Otorhinolaryngol Head Neck Surg 2019;5:345-51. 